\title{
An unusual presentation of mucoepidermoid carcinoma of the parotid gland
}

\begin{abstract}
We present an unusual case of mucoepidermoid carcinoma of the parotid gland in which the patient reported the presence of the lesion since childhood and initially suspected to represent a first branchial cleft cyst. Preoperative imaging found a cystic lesion in the superficial lobe of the parotid gland without associated lymphadenopathy. After surgical excision, pathology revealed a unicystic lesion lined by cuboidal to columnar and some squamoid cells with positive mucicarmine staining and MAML2 rearrangement strongly suggesting mucoepidermoid carcinoma.
\end{abstract}

Keywords: mucoepidermoid carcinoma, major salivary gland neoplasms

\author{
Volume 4 Issue 3 - 2017
}

\author{
Amanda Allen DO,' Nitu Saran DO,' \\ Mohammad Shokouh-Amiri, ${ }^{2}$ John V Groth ${ }^{2}$ \\ 'Department of Radiology, University of Illinois Hospital and \\ Health Sciences System, USA \\ ${ }^{2}$ Department of Pathology, University of Illinois Hospital and \\ Health Sciences System, USA
}

\begin{abstract}
Correspondence: Amanda Allen, Department of Radiology, University of Illinois Hospital, I740 W Taylor Street, IL 606 I2, Chicago, USA, Tel 32199600 I I,

Email Amanda.allen05c@gmail.com
\end{abstract}

Received: October 16, 2017 | Published: October 26, 2017

\section{Introduction}

Malignant tumors of the salivary gland are uncommon encountered neoplasms of the head and neck. Mucoepidermoid carcinoma is the most common malignant neoplasm of the salivary glands with the parotid gland most frequently involved. ${ }^{1}$ Benign and malignant neoplasms have variable appearance on imaging and difficult to accurately differentiate. We present a case of mucoepidermoid carcinoma of the parotid gland with an unusual clinical presentation.

\section{Case presentation}

A 33year-old woman was referred to our institution with complaint of an enlarging mass in the right cheek and jaw. She reported that the mass had been present since childhood, but did notice it increasing size over the past few months and requested removal. Physical exam revealed a firm, mobile mass fixed to the right parotid tail. Contrast enhanced CT of the neck demonstrated a $2.1 \times 2.2 \times 1.9 \mathrm{~cm}$ predominantly cystic mass in the right parotid gland superficial lobe with a thin peripheral rim of enhancement (Figure $1 \&$ Figure 2). No associated lymphadenopathy was identified. As the lesion was reported to have been present since childhood, a first branchial cleft cyst was favored based on imaging characteristics and location. The mass was found to be predominantly superficial to the fascia intraoperatively and extended minimally into the preparotid fascia at the central aspect. H\&E stained images showed a relatively unicystic lesion, lined predominantly by cuboidal to columnar cells, some with possible cilia, with squamoid cells and some mucus producing cells (Figures 3). Mucicarmine stain brightly highlighted the mucin producing cells (Figure 4). Additionally, lesional cells demonstrated expression of MAML2 rearrangement by fluorescence in-situ hybridization. The combination of these findings strongly supported the diagnosis of low grade mucoepidermoid carcinoma.

Discussion: Salivary gland tumors are reported to account for only $2 \%$ of neoplasms of the head and neck. ${ }^{2,3}$ Additionally, less than $25 \%$ of salivary gland neoplasms are malignant with mucoepidermoid carcinoma being the most common. ${ }^{1}$ Most cases of mucoepidermoid carcinoma are found in the parotid gland. Rapid growth is unusual; however, cases have reported growth after a period of quiescence. ${ }^{4}$ Although benign and malignant tumors cannot be differentiated by imaging, there are some features that can be utilized. Benign tumors tend to be sharply circumscribed while malignant tumors more often demonstrate irregular and infiltrating margins. ${ }^{5}$ MR imaging should be considered preoperatively as it is more sensitive in evaluating tumor components and is particularly useful in evaluating for perineural invasion, an important prognostic indicator. A helpful MR imaging feature of high grade tumors is low signal intensity on T2 weighted images which is believed to reflect the high-cellularity of tumor cells. ${ }^{67}$ Furthermore, the identification of perineural spread is also predictive of high grade tumors. ${ }^{7}$ In contrast to low grade lesions which are reported to demonstrate higher signal intensity on T2 weighted images due to the presence of mucin secreting cells. ${ }^{6}$

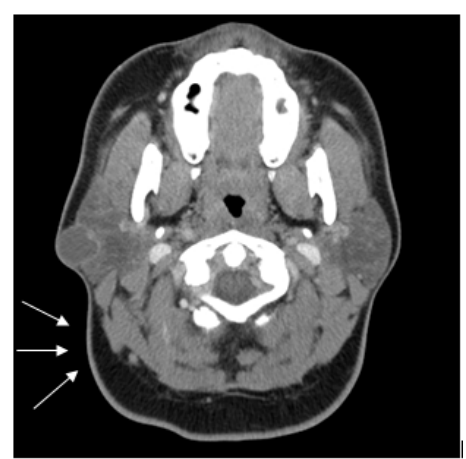

Figure I Contrast enhanced axial CT of the neck shows a cystic lesion in the superficial lobe of the right parotid gland with thin rim of peripheral enhancement.

Histologically, mucoepidermoid carcinoma is characterized by proliferation of secretory cells with variable cell components including squamoid, columnar and clear cells often with a cystic component and capable of producing mucous. ${ }^{1,4}$ Histologic grading is based on the intracystic component, neural invasion, mitosis, necrosis and anaplasia. ${ }^{1,3,5}$ High grade varieties are more solid and 
have an infiltrative pattern of growth while low grade tumors are often cystic. ${ }^{8,9}$ Mucus producing cells predominate in the low-grade tumors and the squamous cells are predominant in the high-grade tumors. ${ }^{8,9}$ Gene fusions involving MAML2 has been shown to be specific for mucoepidermoid carcinoma and diagnostically useful. ${ }^{10}$

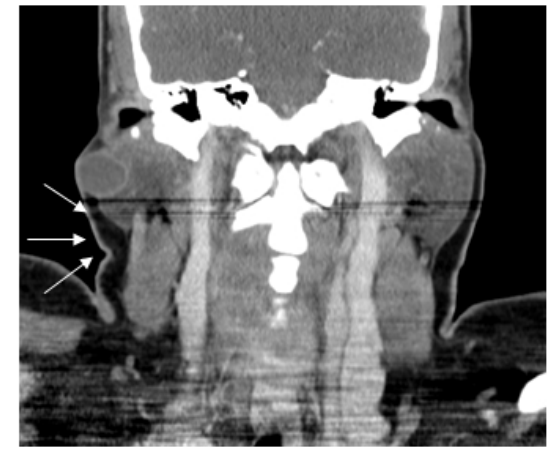

Figure 2 Contrast enhanced coronal CT of the neck shows a cystic lesion of the superficial lobe of the left parotid gland.

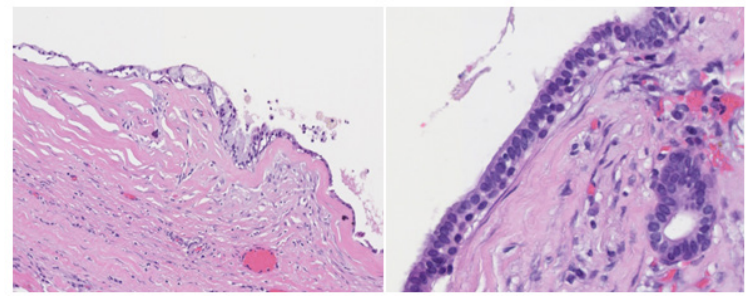

Figure 3 H\&E stain showing columnar to cuboidal epithelial cells, some with possible cilia with cystic components and mucin production.

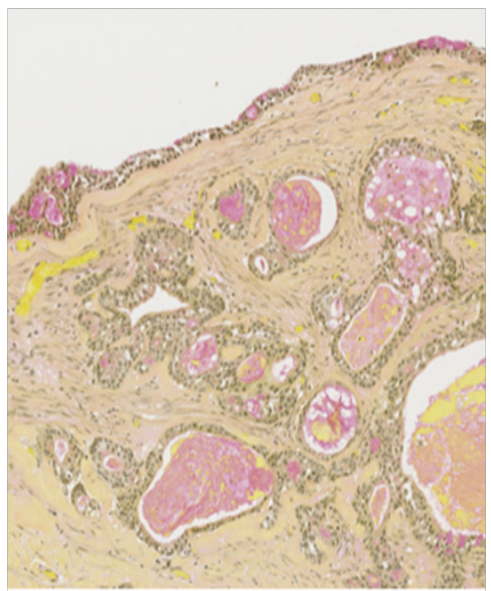

Figure 4 Mucicarmine stain demonstrates intracytoplasmic mucin staining within lesional cells.

\section{Conclusion}

Mucoepidermoid carcinoma of the parotid gland is a relatively uncommon lesion of the head and neck. We present an unusual case in which the patient reported the presence of the lesion since childhood and initially suspected to represent a first branchial cleft cyst. MR imaging is the most useful in differentiating low grade from high grade tumors while allowing evaluation for perineural invasion. These findings combined with characteristic histopathology allows for accurate diagnosis.

\section{Acknowledgements}

None.

\section{Conflict of interest}

Author declares that there is no conflict of interest.

\section{References}

1. Ellis GL, Auclair PL, Gnepp DR. Surgical pathology of the salivary glands. Philadelphia, USA: WB Saunders; 1991.

2. Mafee M, Venkatesan T, Ameli N, et al. Tumors of Parotid gland and Parapharyngeal Space: Role of Computed Tomography and Magnetic Resonance Imaging. Operative Techniques in Otolaryngology-Head and Neck Surgery. 1996;7(4):348-357.

3. Spiro RH. Salivary neoplasms: overview of a 35-year experience with 2,807 patients. Head Neck Surg. 1986;8(3):177-184.

4. Guevara-Canales J, Morales-Vadillo R, Guzman-Arlas G, et al. Mucoepidermoid carcinoma of the salivary glands. A Retrospective study of 51 cases and review of the literature. Acta Odontol Lathnoam. 2016;29(3):230-238.

5. Pires FR, Pringle GA, de Almeida OP, et al. Intraoral minor salivary gland tumors: a clinicopathological study of 546 cases. Oral Oncol. 2007;43(5):463-470.

6. Kashiwagi N, Dote K, Kawano K, et al. MRI findings of mucoedidermois carcinoma of the parotid gland: correlation with pathologic features. The British Journal of Radiology. 2012;85(1014):709-713.

7. Christe A, Waldherr C, Hallett R, et al. MR Imaging of Parotid Tumors: Typical Lesion Characteristics in MR Imaging Improve Discrimination between Benign and Malignant Disease. AJNR Am J Neuroradiol. 2011;32(7):1202-1207.

8. Rosai J. Rosai and Ackerman's Surgical Pathology. 10th ed. Canada: Elsevier; 2011.

9. Cibas E, Ducatman B. Cytology: Diagnostic Principles and Clinical Correlates. 3rd ed. Netherlands: Elsevier; 2010.

10. Bishop JA, Cowan ML, Shum CH, et al. MAML2: Rearrangements in Variant Forms of Mucoepidermoid Carcinoma: Ancillary Diagnostic Testing for the Ciliated and Warthin-like Variants. Am J Surg Pathol. 2018;42(1):130-136. 